\title{
Transmission Spectra Analysis of Lanthanide Super Crystals for Application on Silicon Solar Cell Devices
}

\author{
Alexis Bullock ${ }^{1}$, Marvin Clemmons ${ }^{1}$ \\ ${ }^{1}$ Center for Materials Research, Norfolk State University, Norfolk VA 23504
}

\begin{abstract}
Developing new technologies is essential for advancement in solar cell technologies due to their ability to only absorb light mainly in the visible light spectrum. Super crystals $\mathrm{Nd}^{3+}-\mathrm{Eu}^{3+}$ optical characteristics display higher absorption of light waves than single crystals of $\mathrm{Eu}^{3+}$ and $\mathrm{Nd}^{3+}$ due to a two-photon absorption energy transfer mechanism known as upconversion. Super crystals $\mathrm{Nd}^{3+}-\mathrm{Eu}^{3+}$ display higher absorption due to fewer light waves being transmitted through materials as reported in spectra data. Transmission spectra data reflects that $\mathrm{Nd}^{3+}-\mathrm{Eu}^{3+}$ nanoparticles are great candidates to enhance light absorption in solar cell devices.
\end{abstract}

\section{Keywords}

Inorganic Solar Cells; Absorption; Lanthanides; Transmission; Light waves

\section{Introduction}

Silicon based solar cells are of interest due to their abilities to mainly absorb light in the visible light spectrum (400nm-700nm) [1]. In our research, our goal is to develop crystal nanoparticles from rare earth materials that have the capabilities to transmit less light and absorb more light that is normally lost due reflection, thermalization, and transmission losses. Silicon based solar cells use electromagnetic radiation and devices mainly absorb visible light to covert that energy to power solar cells devices [2]. Super crystals nanoparticles can absorb more light waves due to specific frequencies within the electrons due to visible and infra-red emission that tend to vibrate when incident light excites meta-materials [3]. The vibrational energy is then converted to thermal energy in the $\mathrm{Nd}^{3+}-\mathrm{Eu}^{3+}$ crystals and certain frequencies of light mainly (VIS-IR) light spectrum will be absorbed which increases energy in super crystals $\left(\mathrm{Nd}^{3+}-\mathrm{Eu}^{3+}\right) \mathrm{vs}$. single crystals of $\mathrm{Eu}^{3+}$ and $\mathrm{Nd}^{3+}$. Rare earth super crystals have the possibility to increase energy in silicon solar cells $[1,3]$. Observation of the transmission of light in rare earth meta-materials fabricated in our lab shows when a light wave strikes the crystals, and the electrons vibrate, and the energy is reemitted as a light wave [3,5]. In our research our goals are to observe the transmission spectra of $\mathrm{Eu}^{3+}$ and $\mathrm{Nd}^{3+}$ crystals and compare them to single $\mathrm{Nd}^{3+}-\mathrm{Eu}^{3+} \mathrm{s}$ crystals and observe light transmission in meta-materials fabricated. In observation of spectra work the transmission spectra will show that less light is transmitted in the $\mathrm{Nd}^{3+}-\mathrm{Eu}^{3+}$ super crystals than the single $\mathrm{Eu}^{3+}$ and $\mathrm{Nd}^{3+}$ crystals which displays more absorption of photons. 


\section{Materials}

The following materials were used to conduct the experiment:

Europium $\left(\mathrm{Eu}^{3+}\right)$, Neodymium $\left(\mathrm{Nd}^{3+}\right)$, and 2,2, Bipyridine.

\section{Methods}

Each $\mathrm{Ln}\left(\mathrm{NO}_{3}\right)_{3} \bullet(\mathrm{Byp})_{2}$ single $\mathrm{Eu}^{3+}$ and $\mathrm{Nd}^{3+}$ crystals and $\mathrm{X}_{0.5}(\mathrm{NO})_{3} \mathrm{X}_{0.5}(\mathrm{NO})_{3} \bullet(\mathrm{Byp})_{2}$ super crystals $\mathrm{Nd}^{3+}-\mathrm{Eu}^{3+}$ amount proportional to the elements molecular weight were placed in separate vials and solved in ethanol to obtain 0.1 solution for each individual lanthanide element $[3,4]$. The amount of 2,2'-Dipyridyl was $0.2 \mathrm{M}$ solution was prepared in a separate vial. After vial was placed into sonication for 30 minutes then each solution from the vials were poured into one beaker and mixed together [3,4]. Then the beaker was left for several days in different conditions which included high evaporation by RT, various concentrations of solvent, and seed crystal methods. Then the crystals that were produced from seed crystal or evaporation method were observed under the optical microscope for characterization $[3,4]$.

\section{Table 1: Rare Earth Elements Molecular weight [g/mol]}

\begin{tabular}{|c|c|}
\hline Compound & Molecular Weight $[\mathrm{g} / \mathbf{m o l}]$ \\
\hline $\mathrm{Eu}\left(\mathrm{NO}_{3}\right)_{3} * 5\left(\mathrm{H}_{2} 0\right)$ & $427.640 \mathrm{~g} / \mathrm{mol}$ \\
& \\
\hline $\mathrm{Nd}\left(\mathrm{NO}_{3}\right)_{3} * 1\left(\mathrm{H}_{2} 0\right)$ & $348.240 \mathrm{~g} / \mathrm{mol}$ \\
\hline $2,2^{\prime}$-Bypridyril & $156.19 \mathrm{~g} / \mathrm{mol}$ \\
\hline
\end{tabular}




\section{Results}

\section{Spectroscopic Transmission Characterization of $\mathrm{Eu}, \mathrm{Nd}$, and Eu-Nd Crystals}

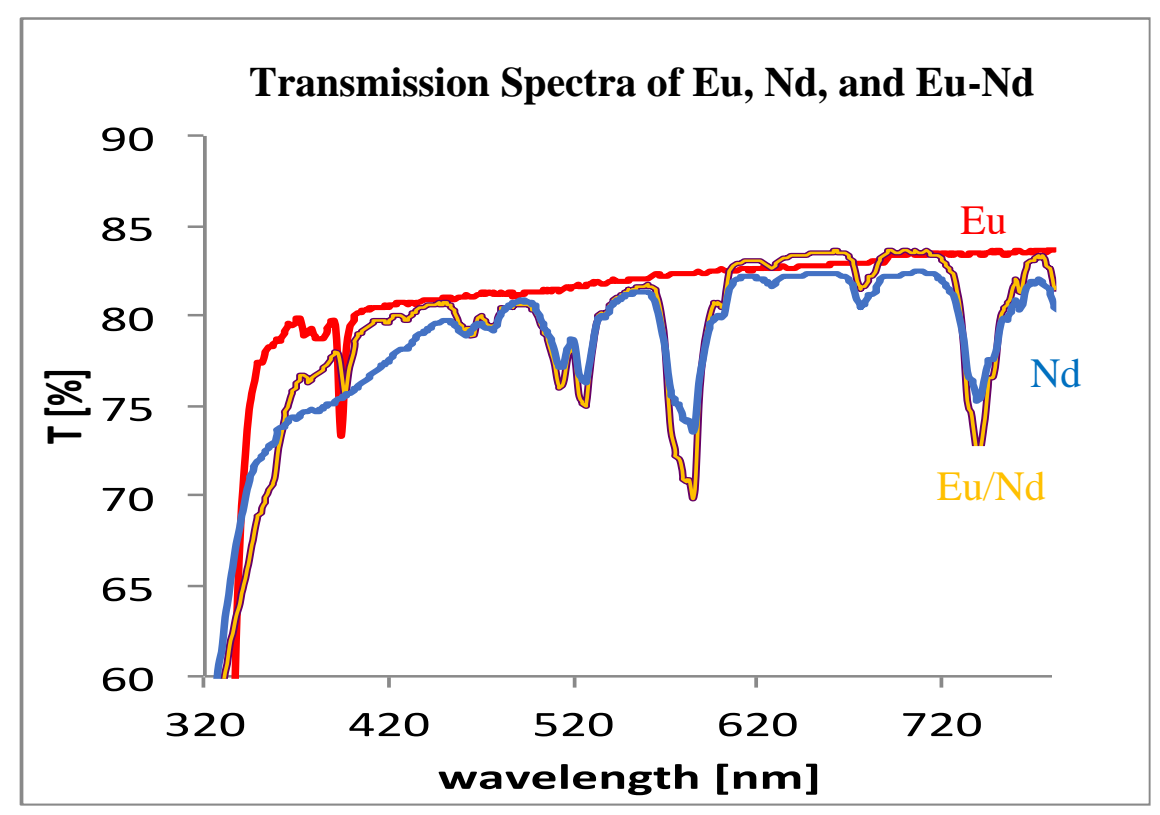

Fig 1. Light waves excited nanoparticles with UV light at (330nm), and $\mathrm{Nd}^{3+}-\mathrm{Eu}^{3+}$ crystals were upconverted (UC) by the two-photon mechanism at peaks $(479 \mathrm{~nm}),(514 \mathrm{~nm}),(527 \mathrm{~nm}),(585 \mathrm{~nm})$ in the visible spectrum, and peak was excited at wavelength $(741 \mathrm{~nm})$ in IR spectrum. Spectra proves that these materials are great candidates to use as spectral converters for solar cell devices.

Light waves excited $\mathrm{Nd}^{3+}-\mathrm{Eu}^{3+}$ nanoparticles crystals with UV light(330nm) utilizing the UVVIS spectrofluorometer instrumentation. Super crystals $\left(\mathrm{Nd}^{3+}-\mathrm{Eu}^{3+}\right)$ were upconverted (UC) by the two-photon energy transfer mechanism at peaks $(479 \mathrm{~nm}),(514 \mathrm{~nm}),(527 \mathrm{~nm}),(585 \mathrm{~nm})$ in the visible spectrum, and at wavelength $(741 \mathrm{~nm})$ in IR spectrum as shown in Fig.1. Transmission spectra data reflects that at the amount of light transmitted in at peaks $(479 \mathrm{~nm}) 49.43 \%,(514 \mathrm{~nm})$ $45.98 \%,(579 \mathrm{~nm}) 45.11 \%$, and for the peak transmitted in the IR spectrum was $(714 \mathrm{~nm})$ measured at $42.53 \%$. Transmission data reflects that less light was transmitted in the $\mathrm{Eu}^{3+}-\mathrm{Nd}^{3+}$ crystals at the referenced peaks $(479 \mathrm{~nm}, 514 \mathrm{~nm}, 527 \mathrm{~nm}$, and $585 \mathrm{~nm})$ which proves that more light is 
absorbed in super crystals $\left(\mathrm{Nd}^{3+}-\mathrm{Eu}^{3+}\right)$ materials due to the UC energy transfer mechanism. These materials can be explored to be used to enhance absorption of energy in silicon solar cell devices.

\section{Discussion}

The upconversion energy transfer mechanism between super crystals $\mathrm{Nd}^{3+}-\mathrm{Eu}^{3+}$ causes the transmission of light waves to be less than single $\mathrm{Eu}^{3+}$ and $\mathrm{Nd}^{3+}$ nanocrystals. Super crystals and single crystals were excited by UV light at the wavelength of $(330 \mathrm{~nm})$ in the UV-Vis spectrofluorometer with specific parameters. These materials were excited when light waves penetrate the crystals and the light that was transmitted through the crystal nanoparticles is shown in the data in the results in Fig.1. The super crystals $\left(\mathrm{Nd}^{3+}-\mathrm{Eu}^{3+}\right)$ specifically were upconverted as reported in previous research data and less light was transmitted in the super crystals which shows more light was absorb in the Nd-Eu super crystals. Fluorescent lanthanides nanoparticles have drawn significant attention due to their major technological applications in scientific and biomedical research. In our research we are successful in analyzing our spectra work (emission and transmission) to shown how super crystal nanoparticles react to UV light waves. 


\section{Conclusion}

In conclusion crystals quality demonstrated high efficiency in transmission spectra and are suitable for application on silicon based solar cell devices [2,5]. Rare earth lanthanides $\mathrm{Nd}^{3+}-$ $\mathrm{Eu}^{3+}$ ions materials have great optical quality and exhibit less transmission of light through the $\mathrm{Nd}$-Eu nanoparticles in comparison to single $\mathrm{Eu}^{3+}$ and $\mathrm{Nd}^{3+}$ nanoparticles due to upconversion processed as reported in previous research [2]. Materials can be applied to further solar cell studies to absorb more photons from the solar light spectrum. Lanthanides have spectroscopic features and their absorption, emission bands, and energies for each lanthanide ion exhibit qualities for further research and applications in the future. 


\section{References}

1. Science Mission Directorate. "Visible Light" NASA Science. 2010. National Aeronautics and Space Administration. [insert date-e.g., 10 Aug. 2016] http://science.nase.gov/ems/09_visible light.

2. Muhammad Safdar, Amr Ghazy, Mika Lastusaari, and Marrit Karppinen.Lanthanidebased inorganic-organic hybrid materials for photon-upconversion. Journal of Materials Chemistry, Issue 2, pubs.rcs.org (2020.)

3. Alexis Bullock, Marvin Clemmons. Dr. Sun Shing. "Spectroscopic Analysis of Photonic Lanthanide Nanoparticles used to Harvest Photonic Energy." MRS Advances (2021). http:/doi.org/10.1557/s43580-021-00088-z

4. R Hussain, A Bullock, D Gable, J Griffin, N. Noginova, “Organic Lanthanide Crystals for Nano-Optics Studies", MRS Advances 1-5 (2015).

5. David S. Bradshaw and David L. Andrews, "Optical Control through light Transmission," Optics \& Photonics News 22(7), 52-57 (2011) 